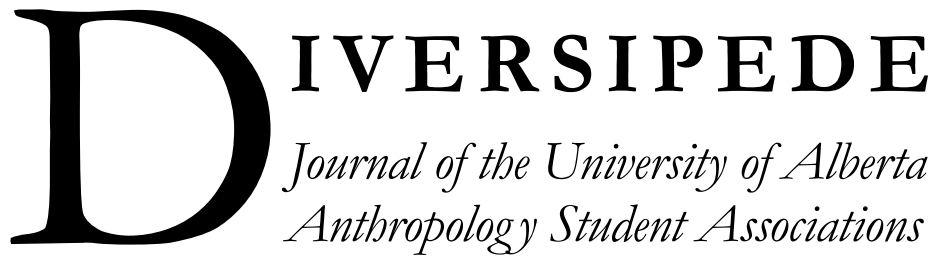

Volume 1

April 2011

Number 1

\section{Identification of a Palaeoindian Occupation in Compressed Stratigraphy: A Case Study From Ahai Mneh (FiPp-33)}

\author{
Matt Rawluk, Aileen Reilly, Peter Stewart, \& Gabriel Yanicki
}

The 2010 University of Alberta Institute of Prairie Archaeology field school produced thousands of artifacts including diagnostic projectile points that provide evidence of multiple occupations spanning a 10,000 year period. As is typical of archaeological sites with limited surface deposition, a lack of visible stratigraphy makes it difficult to associate the assemblage with these temporal and cultural diagnostics, or assess changing occupation patterns over time. The authors present here a method reliant upon diligent attention to three-point proveniencing and analysis using low-cost, easily accessible software to complement the otherwise weak stratigraphic record; the resulting empirically segregated data show multiple components, the earliest of which correlates with an Agate Basin/Hell Gap complex occupation.

A hai Mneh (FiPp-33) is a prehistoric archaeological site located on a high ridge approximately $5 \mathrm{~km}$ south of Wabamun Lake in west-central Alberta (Figure 1). The site was first identified in 1979, and at that time was recorded as an isolated find (Fedirchuk 1979). Subsequent investigation revealed that the site was much larger than originally assessed (Ball 2006), and in the fall of 2008, at the request of TransAlta Generation Partnership, archaeological excavation was undertaken at the site by Altamira Consulting Ltd. under the direction of Kristin Soucey. The analysis of material from the site indicated that it was a multicomponent, prehistoric campsite spanning over 10,000 years (Soucey, Ball and Boscher 2009). The site was given the name Ahai Mneh, Nakoda for looking glass or mirror (a reference to Wabamun Lake), by Paul First Nation elder Violet Poitras in a naming ceremony held on May 19, 2010.

Further excavations took place from May through August of 2010 as part of a course in archaeological field methods run by the Institute of Prairie Archaeology at the University of Alberta. During the 2010 field season, two separate areas at Ahai Mneh were excavated: Area A, located at the bottom of a swale north of the area excavated in 2008, and Area B, situated on the highest elevation at the site, a small knoll northwest of the 2008 excavation block. This hilltop is in turn the highest landform in the Wabamun Lake area, with the next highest point being Buck Mountain, a prominent foothills outlier $54 \mathrm{~km}$ to the south.

An abundance of highly fragmented faunal remains in Area A, and the presence of a boiling pit filled with calcined bone, indicate that this part of the site was used for food processing. Area B, meanwhile, offered a commanding view of the surrounding area - a minimal distribution of faunal remains, despite the presence of a hearth, and a large amount of debitage are consistent with use

A poster by M. Rawluk and A. Reilly of research discussed in this paper received the Undergraduate Poster Award at the 2011 Richard Frucht Memorial Conference.

M. Rawluk and A. Reilly, undergraduate students; P. Stewart and G. Yanicki, graduate students; Institute of Prairie Archaeology, Department of Anthropology, University of Alberta Author contact:s rawluk@ualberta.ca and reilly@ualberta.ca

Diversipede, Vol. 1, No. 1, pp. 1-15, 2011 


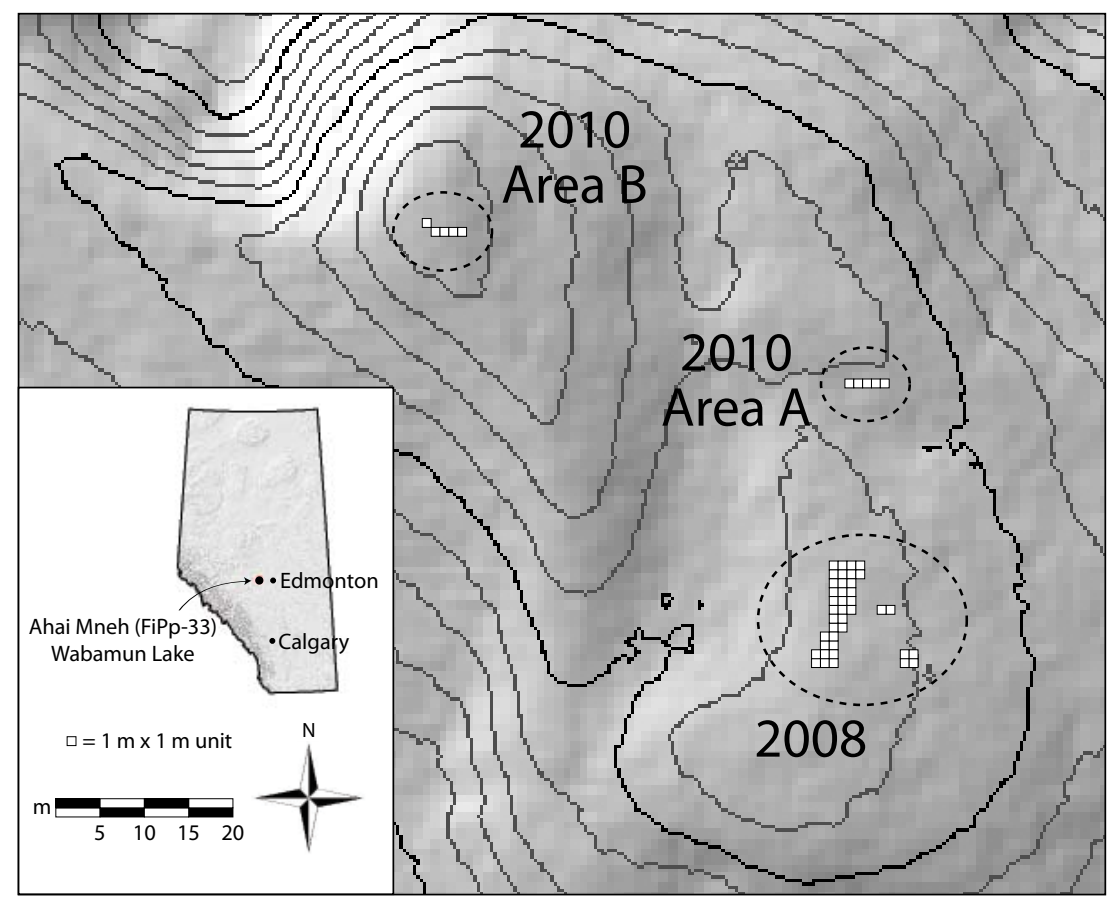

Figure 1: Location of 2008 (Soucey, Ball and Boscher 2009) and 2010 excavation areas at Ahai Mneh (FiPp-33). LiDAR base maps provided courtesy of Robin Woywitka, Archaeological Survey of Alberta; elevation contour $1 \mathrm{~m}$.

as a hunting stand or observation point (Binford 1978, 282; Stevenson 1991). Both areas excavated in 2010 featured shallow stratigraphy, with the majority of the material being recovered within 30 to $40 \mathrm{~cm}$ of the surface. These findings were identical to that of Soucey and colleagues (2009, 54), who noted that the lack of substantial stratigraphy in the units excavated hindered analysis of the archaeological phases and complexes that might be present.

Ahai Mneh is an example of an important kind of site in Alberta - where there is a rich and ancient archaeological record, but thin or compressed stratigraphy resulting from limited deposition of sediments. These sites hold valuable information, but it is difficult to determine which artifacts belong with each other in terms of the time periods represented. Misinterpretations of these archaeological records can arise if these stratigraphic difficulties are not taken into account, but much valuable information can also be sacrificed if these records are discounted in their entirety.

Spatial analytical approaches can definitely help with the objective horizontal segregation of synchronous artifact clusters (e.g., Ives 1985a, 1985b). Another approach is to pay close attention to remnant traces of stratigraphy in these archaeological records. At the depositionally similar Strathcona Science Park site (FjPi-29), Pyszczyk (1981) showed that projectile point forms tended to obey their correct chronological order even in a compressed stratigraphic setting. Following this example, our analysis of the lithic assemblage from the 2010 excavations focused on determining whether multiple discrete components could be identified at Ahai Mneh. In so doing, a simple and low-cost method was devised that can readily be adapted for use at other rich sites with compressed stratigraphy, a common problem in boreal forest and parkland archaeology.

Although the uppermost deposits have proven too dense, and possibly disturbed through bioturbation, for individual components to be empirically segregated, a distinct lower occupation was identifiable in both areas characterized by a matching pattern of lithic material utilization and the presence of Agate Basin/Hell Gap projectile 
M. Rawluk, A. Reilly, P. Stewart, \& G. YANICKI

points. ${ }^{1}$ This finding has broadened our understanding of an occupation tentatively identified in the previous excavation (Soucey, Ball and Boscher 2009, 60) and provides a base of reference for comparison to other similarly aged occupations, a rarity at excavated sites in Alberta (Benders 2010; Fedje 1986, 1988; Landals 2008; Peck 2011; Reeves 1972; Ronaghan and Dawe 1998).

\section{Methodology}

Decisions made from the outset of excavation in the 2010 field school through to the conclusion of cataloguing had a direct impact on the nature and quality of the data available, and are discussed briefly in this section. While excavating, it quickly became apparent that stratigraphy was to a certain extent intact, particularly as older styles of projectile points were found in progressively deeper layers. However, the pronounced slope of ground surfaces and buried strata coupled with bioturbation factors such as rodent burrows and
Identification of a PaLAeoindian OCCupation in COMPRESSED STRATIGRAPHY

tree roots, as well as generally shallow deposition, presented challenges for stratigraphically associating artifacts. Subsequent analysis focused on whether the excavation areas could be separated into discrete components using low-cost and readily available tools. This included 3D modeling of the lithic assemblage using Apple's Grapher Version 1.1, which provided a qualitative visual overview of the site; devising a mathematical method to correct for slope, which enabled comparison by depth across units with varied microtopography; and quantitative analysis using Microsoft Excel, which allowed for more robust characterization of changes in site utilization over time.

\section{Excavation procedures}

Continuing from the $441 \mathrm{~m}$ by $1 \mathrm{~m}$ excavation units opened in 2008 (Soucey, Ball and Boscher 2009), five units each were laid out on an east-west axis in Area A (Units 45-49) and Area B (Units 50-54), with the westernmost unit in Area
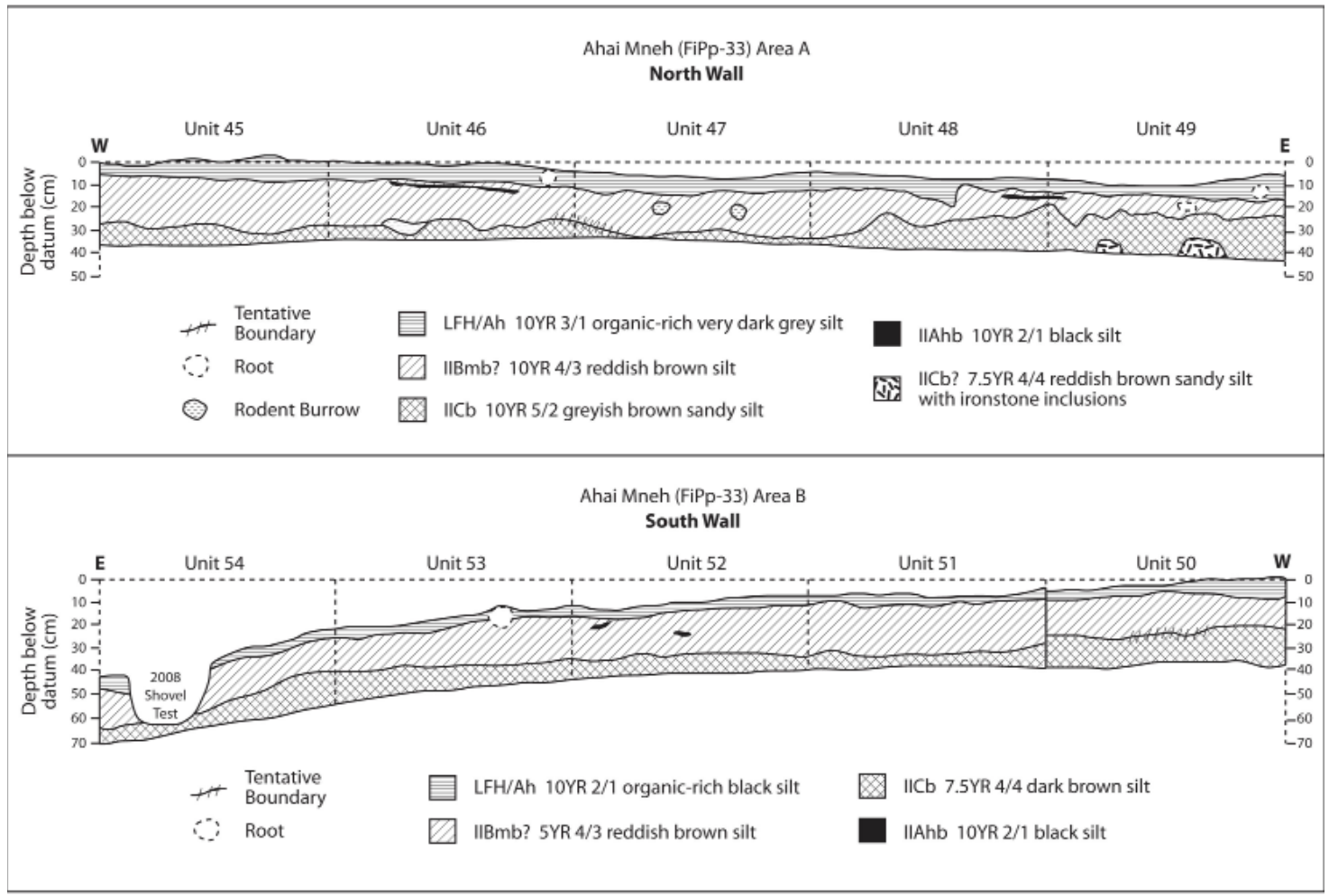

Figure 2: Soil profiles, Areas A and B. Note Unit 50 is offset by $1 \mathrm{~m}$ to the north.

${ }^{1}$ For a more detailed description of the Early Prehistoric projectile points from Ahai Mneh, see Schenk and Yanicki, this volume. 
B offset one metre to the north to avoid an old shovel test (Figure 2). Excavation was conducted by trowel in five centimetre arbitrary intervals, with all matrix screened through $6.35 \mathrm{~mm}\left(1 / 4^{\prime}\right)$ wire mesh. Measurements were made from the southwest corner of each unit, with the surface depth of each corner recorded relative to an arbitrary fixed datum.

The critical dimension of this work was careful attention to the recovery of three point provenience data for in situ lithics. Northing, easting and depth below datum were recorded for a total of 1,894 stone artifacts, including debitage and tools, comprising $75.0 \%$ of the excavated lithic assemblage. A further 631 unprovenienced lithic artifacts, mostly small retouch flakes and fragments, were recovered during excavation, mostly by screen. In both areas, cultural material was found to a depth of approximately $30-40 \mathrm{~cm}$ below surface, after which excavation proceeded by shovel for a further $10 \mathrm{~cm}$ to confirm sterile parent sediment had been reached.

\section{Cataloguing}

For consistency of results between the 2008 and 2010 excavations, the cataloguing guidelines followed were the same as those used by Soucey and colleagues $(2009,31)$, adapted from Andrefsky (1998) and Le Blanc (1994). Attributes including flake, tool or core type; colour using Munsell colour charts; size; weight; and flake attributes such as amount of cortex and number of dorsal scars were recorded in a spreadsheet using Microsoft Excel. The present study focused on provenience and raw material type; additionally, projectile point styles were taken into consideration in assessing the identified components.

Eleven raw material types - quartzite, porcellanite, siltstone, chert, mudstone, chalcedony, flint, limestone, silicified peat, petrified wood, and sandstone - were previously identified at Ahai Mneh, with $80 \%$ of the assemblage consisting of quartzite (Soucey, Ball and Boscher 2009, 55). Most of these materials, with the exceptions of flint, petrified wood, limestone, and sandstone, were observed in the 2010 excavation assemblage, while pebble chert, agate, quartz, and obsidian, not previously observed at the site, were recorded. Some raw materials were locally available, with proximity to the North Saskatchewan River providing ready access to modifiable cobbles, particularly quartzite, and possibly siltstone, limestone, and sandstone. Porcellanite also likely had local sources (Soucey, Ball and Boscher 2009, 57), and might have formed in sediments adjacent to coal seams ignited by spontaneous combustion; exposures of such naturally fired material probably formerly occurred throughout the surrounding TransAlta Highvale Mine lease area. Other raw material types are more exotic, either coming from elsewhere in Alberta (for instance, petrified wood, mudstone, silicified peat, quartz, and some cherts including pebble chert), or even further afield (agate, flint, chert, chalcedony, and obsidian) (Bob Dawe, pers. comm.).

\section{$3 D$ modeling}

To create a three dimensional rendering of the lithic assemblage of the site, three point provenience data was entered into Apple's Grapher Version 1.1. Grapher allows data to be plotted on three axes, $x, y$, and $z$, where $x$ would be the easting provenience of an in situ artifact, $y$ would be its northing, and $z$ would be its depth below datum. Further, data sets can be grouped in clusters that are visually represented by different colours or symbols, and the resulting 3D scatterplot can be rotated for multiple views. Other programs, notably ArcGIS, can accomplish similar tasks but require training and are costly to license, while Grapher is a pre-installed application that is readily available to researchers operating on a limited budget.

Separate 3D models were made for Area A and Area B. To be rendered accurately in Grapher, some data needed to be adjusted. With easting and northing expressed as a value between 0.0 $\mathrm{cm}$ and $100.0 \mathrm{~cm}$ in each excavation unit, for instance, if input directly, all units would overlap in a single $1 \mathrm{~m}$ by $1 \mathrm{~m}$ frame. For Area A, to express the site as a $1 \mathrm{~m}$ by $5 \mathrm{~m}$ long trench running east to west, a modified easting was entered, adding a cumulative distance of $100 \mathrm{~cm}$ for every unit to the east of the westernmost Unit 45 (i.e., $100 \mathrm{~cm}$ was added to all eastings in Unit 46, $200 \mathrm{~cm}$ was added in Unit 47, and so on). For Area B, a cu- 
M. Rawluk, A. Reilly, P. Stewart, $\&$ G. YANICKI

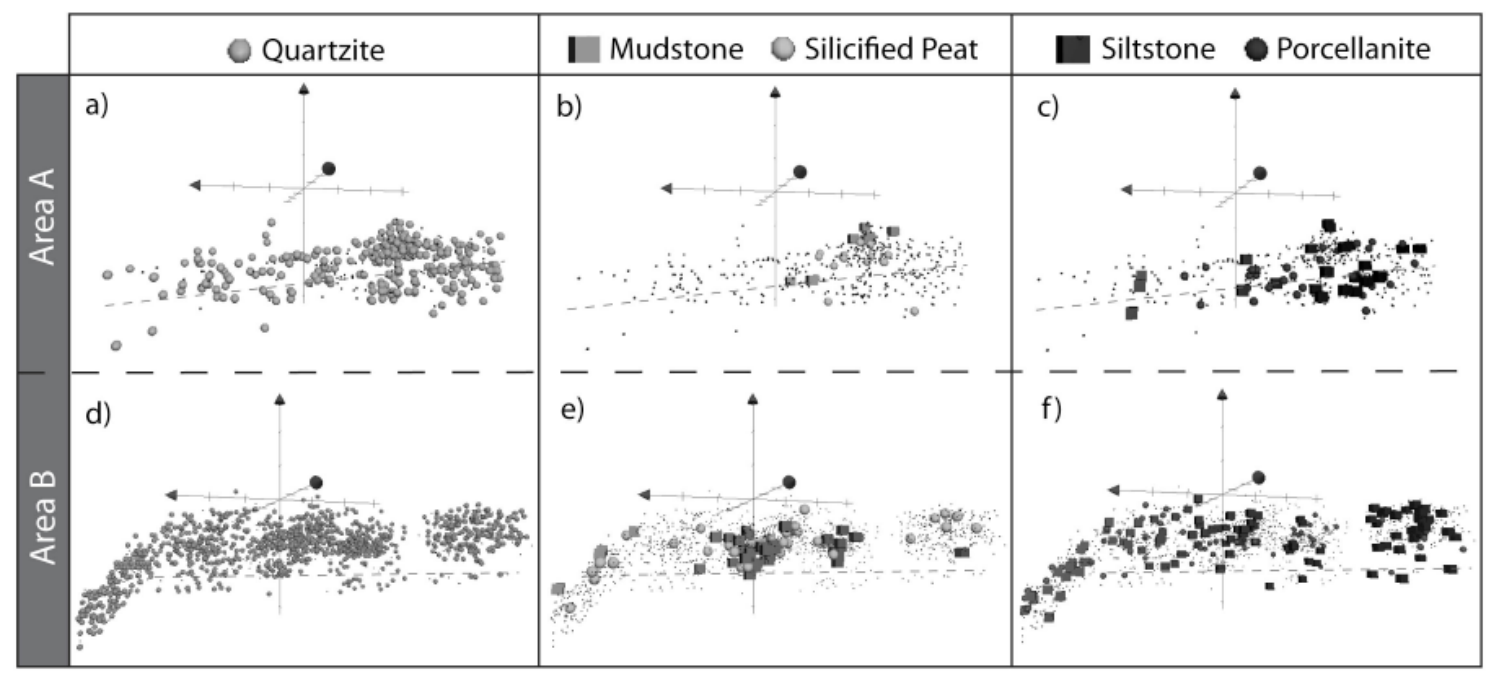

Figure 3: Raw scatterplots from Grapher of material spatial distributions in Areas A and B plotted against all other lithics (small dots). Note in $b$ and $e$ a maximal depth, indicated by dashed line, beyond which mudstone and silicified peat generally do not occur, but more locally sourced materials such as quartzite, siltstone and porcellanite do. In Area A, this maximal depth corresponds with a visible gap in deposition.

mulative distance of $100 \mathrm{~cm}$ was added for every unit east of Unit 50, and to account for that unit's $1 \mathrm{~m}$ offset to the north, $100 \mathrm{~cm}$ was also added to that unit's northings.

Depth values also required adjustment. First, all measurements made relative to units' respective southwest corners were adjusted to reflect their depth relative to their area's fixed datum. The variable surface topography of the two excavation areas was therefore accurately portrayed. Next, if entered as positive values on the $z$ axis, artifact depths would be rendered upside down and rising progressively above surface. All depths were therefore multiplied by -1 , rendering them as descending negative values. Finally, the shallow deposition of the site proved to be an obstacle when viewing the $3 \mathrm{D}$ model rendered thus far - any possible gaps in vertical deposition that could indicate breaks in occupation were obscured in such a tightly grouped cluster. Depths in the 3D model therefore were exaggerated; after trying a number of arbitrary settings, we found multiplying depths by a factor of five made potential trends better observable, while also emphasizing sloped deposition.

A final step involved inputting the proveniences for each raw material type as separate data groups into Grapher. This allowed trends in the spatial distribution and association of different raw materials to be visually assessed (Figure 3). Further insight was provided by plotting in the locations of diagnostic projectile points (Figures 8 and 10).

\section{Correcting for slope}

3D modeling shows that lithic deposits in both Areas A and B occurred on a slope. In Area A, the gradient of the buried artifacts does not correspond with the surface microtopography, which was generally flat. However, a visible break in deposition (indicated by a dashed line in Figure 3, $a, b$ and $c$ ) corresponds with the general sloping trend of the buried artifacts. In Area B, the surface sloped increasingly downward to the east, being especially pronounced in the easternmost Unit 54. Deposition followed the surface contour in Units 50, 51, and 52, but in Units 53 and 54, the gradient of buried deposits was slightly less than the surface contour, better corresponding with the gradient of the buried A horizon (Figure 2). In both areas, slope was negligible from south to north, but within individual units, the difference in surface depth below datum between west and east corners varied between 0 and $20 \mathrm{~cm}$. 
The stratigraphic association of artifacts based on depth below datum would be impossible to statistically demonstrate without taking this highly variable microtopography into consideration - using unmodified depth measurements, artifacts even from the opposite sides of the same unit could come from entirely different cultural occupations. To correct for slope, mathematically described as rise over run $(\Delta y /$ $\Delta x)$, we devised a calculation to cancel out the rise, or depth of an artifact attributed purely to slope, from an artifact's depth below datum over a given run, in this case the artifact's easting or a portion thereof. The result of this calculation would be an equivalent depth if the assemblage were distributed over a level plane, enabling the statistical assessment of whether artifacts are stratigraphically associated. The following procedure was applied:

1. Determine the total rise and run

2. Determine the individual artifact's easting $(E)$ as a fraction of the total $\operatorname{run}(\Delta x)$.

3. Multiply the artifact's fraction of total run, determined in step 2 , by the total rise $(\Delta y)$.

4. Subtract the results from step 3 from the depth $(D)$ of the artifact. The depth is now equivalent to being on a slope of $0 \mathrm{~cm}$ rise.

For example, a $1 \mathrm{~m}$ by $1 \mathrm{~m}$ excavation unit has no slope from north to south, but its east side is one centimetre lower than its west. Total run $(\Delta x)$ is therefore $100 \mathrm{~cm}$, and total rise $(\Delta y)$ is $-1 \mathrm{~cm}$. Once the calculation is applied, for an artifact with an easting (E) of $0 \mathrm{~cm}$, the expected reduction in depth $(D)$ would be $0 \mathrm{~cm}$ (see Example A below). For an artifact with an easting of $100 \mathrm{~cm}$, the expected reduction of depth would be $1 \mathrm{~cm}$ (Example B). For an artifact with an easting of $50 \mathrm{~cm}$ (half of the total run), depth should be reduced by half of the total rise, or $0.5 \mathrm{~cm}$ (Example C). If all three artifacts had been found on the surface, starting depths below datum of $0 \mathrm{~cm},-1.0 \mathrm{~cm}$, and -0.5 $\mathrm{cm}$ respectively would now be adjusted to $0 \mathrm{~cm}$, $0 \mathrm{~cm}$ and $0 \mathrm{~cm}$; slope has been negated.
Example A:

1. $\Delta y=-1 \mathrm{~cm}, \Delta x=100 \mathrm{~cm}, D=0 \mathrm{~cm}$, $E=0 \mathrm{~cm}$

2. $E \div \Delta x=0 \div 100=0$

3. $\Delta y \times(E \div \Delta x)=0 \times 0=0$

4. $D-(\Delta y \times[E \div \Delta x])=0-0=0 \mathrm{~cm}$

Example B:

1. $\Delta y=-1 \mathrm{~cm}, \Delta x=100 \mathrm{~cm}, D=-1 \mathrm{~cm}$, $E=100 \mathrm{~cm}$

2. $E \div \Delta x=100 \div 100=1$

3. $\Delta y \times(E \div \Delta x)=-1 \times 1=-1$

4. $D-(\Delta y \times[E \div \Delta x])=-1--1=0 \mathrm{~cm}$

Example C:

1. $\Delta y=-1 \mathrm{~cm}, \Delta x=100 \mathrm{~cm}, D=-0.5$ $\mathrm{cm}, E=50 \mathrm{~cm}$

2. $E \div \Delta x=50 \div 100=0.5$

3. $\Delta y \times(E \div \Delta x)=-1 \times 0.5=-0.5$

4. $D-(\Delta y \times[E \div \Delta x])=-0.5--0.5=0$ $\mathrm{cm}$

For Area A, the 3D model showed a linear slope to buried artifacts that did not follow natural surface contours. Total rise $(\Delta y)$ and total run $(\Delta x)$ were therefore determined by measuring the distance, in easting and in depth, between the uppermost in situ lithics at the western and eastern ends of the excavation block, resulting in a total rise of $-11 \mathrm{~cm}$ and a total run of 482.5 $\mathrm{cm}$ (Figure 4). Being at the bottom of a swale, it was assumed that this slope represented a former natural surface contour that had been buried by more recent deposition. Because the slope appeared relatively constant, and was mirrored below the visible gap in deposition (Figure 3, $a, b$,

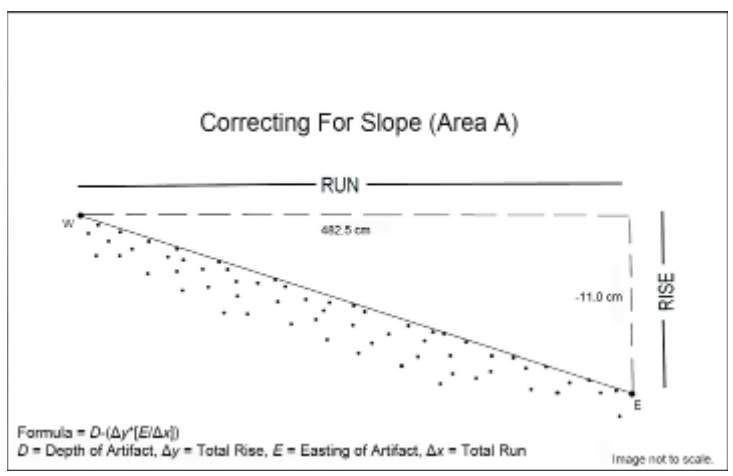

Figure 4: Slope correction in Area A. 
M. Rawluk, A. Reilly, P. Stewart, \& G. YANICKI

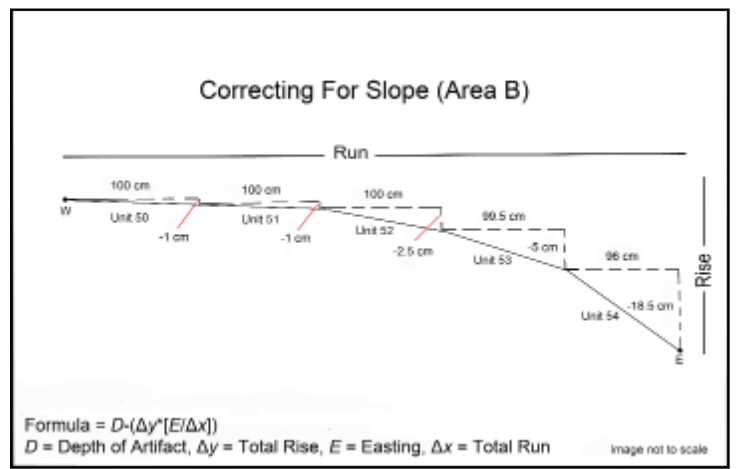

Figure 5: Slope correction in Area B.

and $c$ ), when adjusting for slope, these $\Delta x$ and $\Delta y$ values were applied to all lithics in Area A collectively. Because $\Delta x$ and $\Delta y$ were cumulative for all five excavation units in the area, depths $(D)$ of artifacts in this equation were relative to the area's fixed datum.

In Area B, slope differed between units, and so the formula was applied for each unit individually (Figure 5). For Units 50, 51, and 52, where deposition of artifacts appeared to follow the natural surface contours, rise and the run were derived from measurements of depth below datum of the unit corners, giving runs of $100 \mathrm{~cm}$ and rises of $-1 \mathrm{~cm},-1 \mathrm{~cm}$, and $-2.5 \mathrm{~cm}$, respectively. For Units 53 and 54, where the slope of the buried artifacts appeared to follow the buried A horizon rather than the surface slope, rise and run were calculated from the uppermost in situ lithics at the western and eastern ends of each unit, as in Area A; a run of $99.5 \mathrm{~cm}$ and a rise
Identification of a Palaeoindian OcCupation in Compressed Stratigraphy

of $-5 \mathrm{~cm}$ were thus calculated for Unit 53 , and a run of $96 \mathrm{~cm}$ and rise of $-18.5 \mathrm{~cm}$ for Unit 54 . Because $\Delta x$ and $\Delta y$ were broken down by unit in Area B, the depths $(D)$ of artifacts used in these equations were relative to the southwest corners of their respective units rather than the area's fixed datum.

\section{Empirical data segregation}

Once depth data had been corrected for slope, an attempt could be made to express the patterns observed in the 3D models in quantifiable terms. For each area, a pivot table was generated using Microsoft Excel that sorted artifacts by depth (grouped into $1 \mathrm{~cm}$ increments) and material type. These tables were inspected for evidence of discontinuous occupation and changing trends in lithic raw material utilization, based on which the assemblage could be divided into empirically segregated components. As a final step in this process, these observed trends were compared with the positions of in situ diagnostic projectile points, which allowed the components to be characterized by cultural affiliation (see Results, below).

In Area $\mathrm{A}$, concomitant with the observed trend in the 3D model (Figure 3, $a, b$ and $c$ ), a 1 to $2 \mathrm{~cm}$ break was observed in the depth adjusted data across all units, within which very low numbers of lithic artifacts were present, and higher numbers occurred both above and below. This

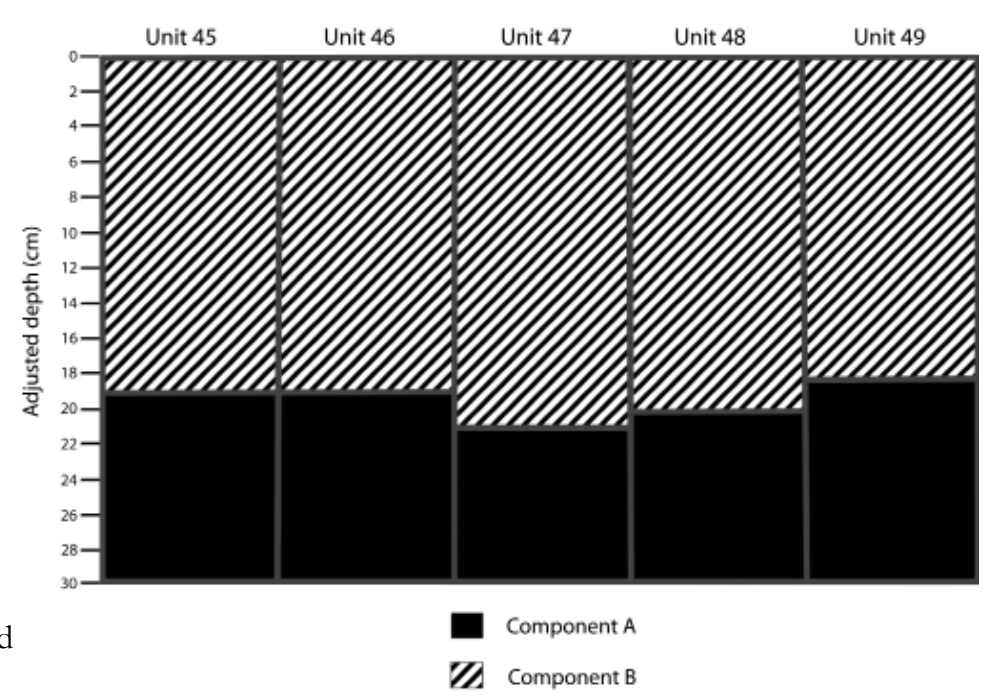

Figure 6: Empirically segregated component depths, Area A 


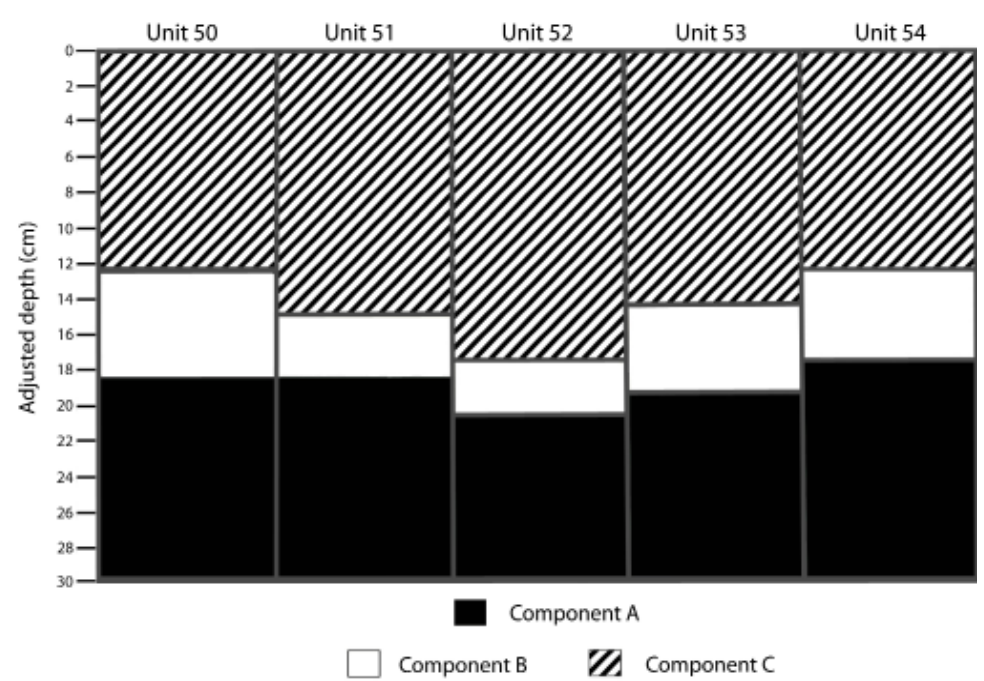

Figure 7: Empirically segregated component depths, Area B

break, interpreted as a discontinuity in occupation, occurred at slightly different depths in different units; the materials below were tentatively assigned to an empirically segregated basal Component $\mathrm{A}$, and the materials above were designated Component B (Figure 6).

Peaks and troughs in the vertical artifact distribution were not as readily identifiable in Area B as in Area A, so rather than segregating components based on the presence of a major break or discontinuity, an attempt was made to identify changing trends in lithic raw material utilization. An ephemeral basal scatter of lithic artifacts consisting exclusively of quartzite, siltstone, and porcellanite had earlier been identified in the 3D model (Figure 3, $d, e$ and $f$ ); pivot table data from slope adjusted depths confirmed this trend across all five units, and the uppermost depths at which these three materials occurred, to the exclusion of any others, was partitioned off as the top boundary of a tentative basal Component A.

Meanwhile, two materials, obsidian and silicified peat, were observed to occur exclusively in the uppermost deposits in the area; the maximal depth at which these occurred was used as the lower boundary for a tentatively identified upper component. This resulted in the tentative identification of a thin medial component in which a broad range of lithic materials occurred, including the only traces at the site of agate and quartz. The medial layer was labelled Component B, and the upper layer was labelled Component $\mathrm{C}$; the resulting partition depths are shown in Figure 7.

These component breaks do not occur at the same depths across all units, and are deepest in Unit 52. The presence of a hearth feature in the upper part of this unit, along with very high quantities of debitage, could suggest trampling associated with heightened activity was a bioturbation factor in this locale. Alternately, the prehistoric microtopography may not have paralleled the surface topography at the time of excavation. Overall, however, patterns of deposition were consistent with adjacent units.

\section{RESUlts}

Area $A$

A total of 398 artifacts were recovered from Area A; of these, four were diagnostic projectile points. The earliest, found in Unit 45, was a small lanceolate specimen that could be a resharpened Agate Basin or Hell Gap point, dating from 10,200-9,600 B.P. (Peck 2011, 55). Additionally, one Oxbow point, ca. 4,500-4,100 B.P. (Peck 2011, 180), one Besant point and one small side-notched point, probably Samantha, each dating from 2,100-1,500 B.P. (Peck 2011, 282) were recovered.

Based on these diagnostics alone, there are indications of at least three temporally distinct cultural occupations in Area A - Agate Basin/ Hell Gap, Oxbow, and Besant; however, only two components could be identified from the depth adjusted data. When plotted against the empiri- 
M. RaWluK, A. Reilly, P. STEWART, \& G. YANICKI
Identification of a PaLAeoindian Occupation in Compressed Stratigraphy

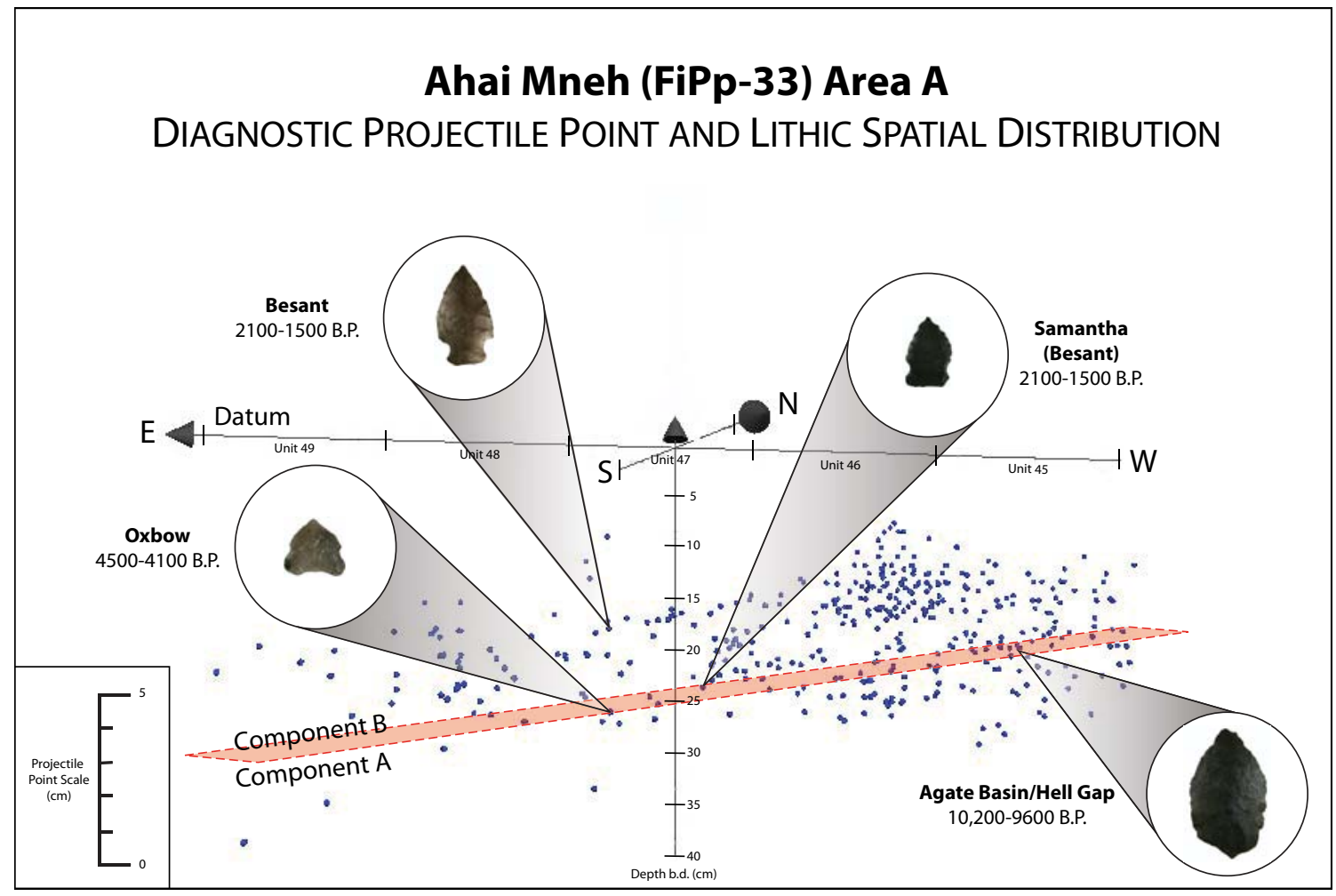

Figure 8: Diagnostic projectile point and lithic spatial distribution, Area A. Date ranges for point styles from Peck (2011).

Figure 9: Raw material distribution by component, Area A. Quartzite, which domi-

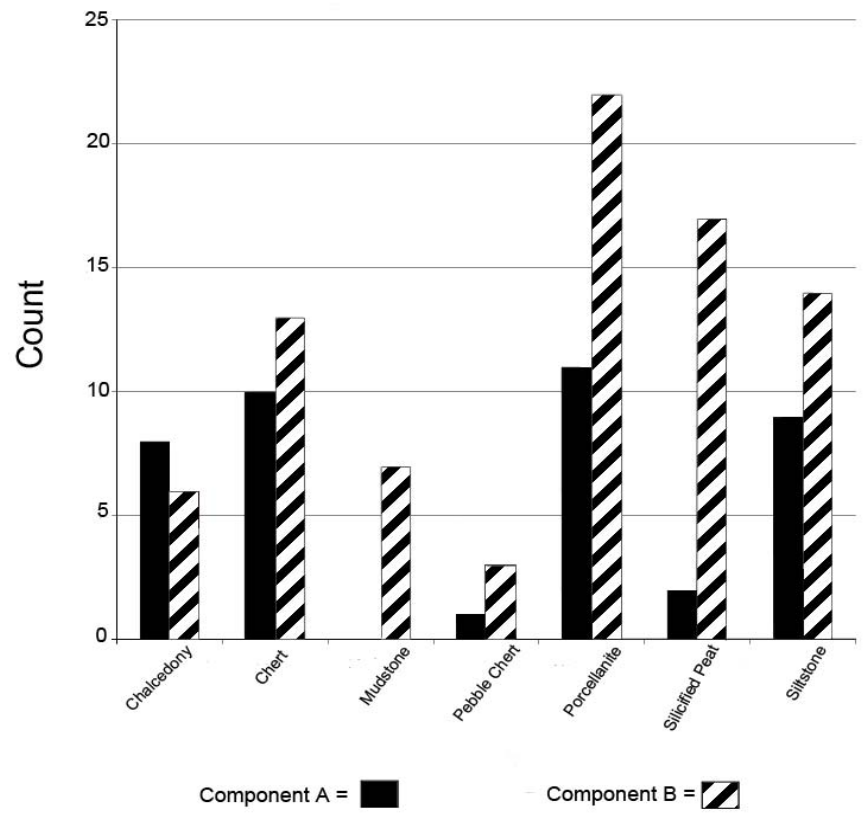
nates both components, is not represented. 


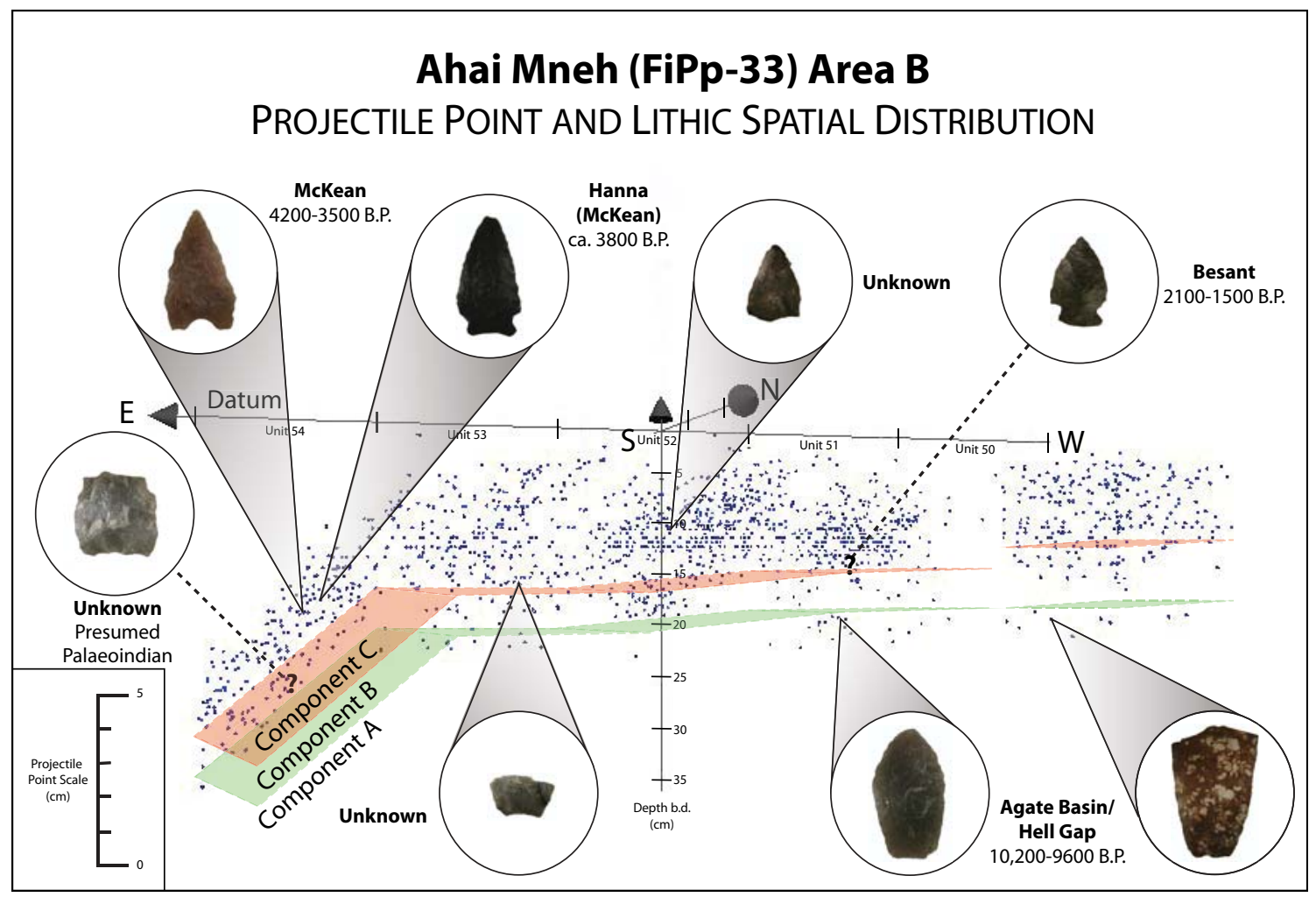

Figure 10: Diagnostic and non-diagnostic projectile point and lithic spatial distribution, Area B. Date ranges for point styles from Peck (2011).

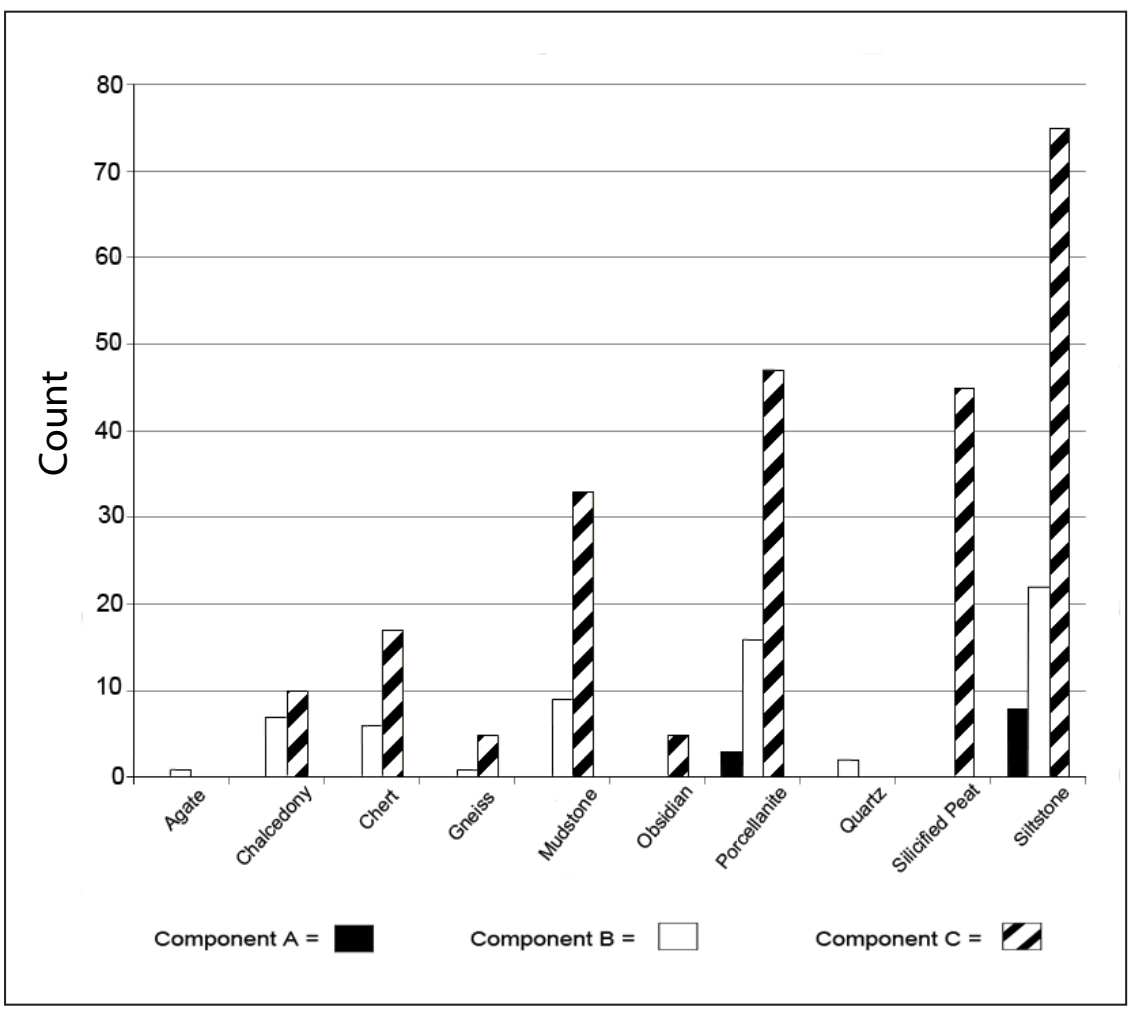

Figure 11: Raw material distribution by component, Area B. Quartzite, which dominates all three components, is not represented. 
M. Rawluk, A. Reilly, P. Stewart, $\&$ G. YANICKI

cally segregated components, the Agate Basin/ Hell Gap point falls within Component A, while the Besant and Samantha points fall within the later Component B; the Oxbow point, meanwhile, appears to fall directly on the boundary between the two (Figure 8). This last is assignable to either Component $\mathrm{A}$ or Component $\mathrm{B}$; the presence of a third component is implied, but its traits are likely obscured within one of the other two components, either above or below the consistent break in deposition that occurs between 19 and $21 \mathrm{~cm}$ across all five units in this area.

In addition to the projectile points being associated with specific components, a number of other trends in lithic utilization are identifiable. In terms of the distribution of raw materials in Components A and B (Figure 9), local materials such as porcellanite, siltstone, and quartzite were abundant in both the upper and lower components, with quartzite making up $67 \%(n=90)$ of the in situ assemblage from Component $\mathrm{A}$ and $69 \%(\mathrm{n}=184)$ from Component B. More exotic materials such as chert, pebble chert, and chalcedony were also found in both components. Two other materials, meanwhile, only become common in the upper component. Seven pieces of mudstone and 17 of silicified peat occur in Component $\mathrm{B}$; in the earlier Component $\mathrm{A}$, mudstone is entirely absent, and there are only two pieces of silicified peat.

Besides the Agate Basin/Hell Gap and possibly Oxbow projectile points, few tools were found in association with Component A. One scraper, one biface fragment, and three unimarginal flake tools were recovered. A bone fragment from the lower part of Unit 46, within Component A, has been sent to the W.M. Keck Carbon Cycle Accelerator Mass Spectrometry Laboratory at the University of California, Irvine for AMS ${ }^{14} \mathrm{C}$ dating.

In Component B, in addition to the Besant and Samantha points, one scraper, four biface fragments, one bimarginal flake tool, three unimarginal flake tools, one combination flake tool, two preforms, and one pièce esquillée were recovered. Calcined bone fragments from an apparent boiling pit in Unit 49 and another fragment from the upper portion of Unit 46, all within this up-
Identification of a Palaeoindian OCCupation in Compressed Stratigraphy

per component, have been submitted for AMS ${ }^{14} \mathrm{C}$ dating.

Area B

A total of 1,535 lithic artifacts were recovered in situ from Area B, of which eight were projectile points. Four in situ projectile points were diagnostic, including two Agate Basin or Hell Gap specimens from the deepest artifactbearing levels in Units 50 and 51 and a McKean (ca. 4200-3500 B.P; Peck 2011, 199) and Hanna point (ca. 3800 B.P.; Peck 2011, 199) from the upper part of Unit 54. Also found in situ were a non-diagnostic triangular projectile point in Unit 52, two projectile point tips from the same unit, and the base of what may be a lanceolate projectile point with a concave basal margin from Unit 53, Level 4. In addition to the in situ materials, a Besant point from Unit 51 and another broken, basally concave lanceolate point from Unit 54 were found in the screen. Given their fragmentary state, the two basally concave lanceolate points cannot reliably be assigned to a diagnostic category, but are presumed to be Palaeoindian in age (see Schenk and Yanicki, this volume).

Based on the diagnostic projectile points alone, at least three separate occupations are inferred to be represented in the assemblage from Area B - Agate Basin/Hell Gap, McKean, and Besant, with the two basally concave lanceolate specimens representing a possible fourth occupation. Only three components could be identified from the depth adjusted data for this area; when plotted against these empirically segregated components, both Agate Basin/Hell Gap points fall within Component $\mathrm{A}$; one of the basally concave lanceolate points occurs on the boundary between Components B and C; and the McKean, Hanna, and triangular points fall within Component C (Figure 10). Despite the lack of three point provenience data for the two points found in the screen, they have tentatively been assigned to components based on the excavation levels from which they were recovered: the basally concave lanceolate specimen likely comes from Component B, while the Besant point likely comes from Component $\mathrm{C}$. Therefore, Components $\mathrm{A}$ and $\mathrm{B}$ are each associated with only one 
projectile point style and may represent individual occupations, while Component $\mathrm{C}$ appears to be an aggregate of at least two temporally dissociated occupations.

Identification of the three components in Area B was founded on the observation that lithic raw material utilization appears to have changed over time. Counts of raw materials by component are presented in Figure 11. The basal Component A, associated with Agate Basin/Hell Gap projectile points, is comprised exclusively of three locally sourced materials: quartzite, which made up $81 \%$ of the assemblage $(n=46)$, porcellanite $(5 \%, n=3)$, and siltstone $(14 \%, n=8)$. Diversification of raw material use increases over time. Eleven different raw materials are associated with Component B; quartzite dominates $(79 \%$ of the component's assemblage, $\mathrm{n}=347)$, while agate $(<1 \%, \mathrm{n}=1)$ and quartz $(<1 \%, \mathrm{n}=2)$, which are found neither above nor below, are present. Component $\mathrm{C}$ is marked by a similar diversity of raw materials, with 11 different materials present; quartzite remains the single most dominant material $(79 \%, \mathrm{n}=851)$, while silicified peat $(4 \%$, $\mathrm{n}=38)$ and obsidian $(<1 \%, \mathrm{n}=5)$ are present. Intensity of site occupation, as an expression of visitation frequency and/or duration, also appears to change over time. Total counts of lithic artifacts increase steadily from 57 artifacts found in situ in Component A to 434 in Component B and 1,075 in Component C.

Aside from the two Agate Basin/Hell Gap projectile points, only one other lithic tool, an edge modified flake, was found in association with Component A. Charcoal fragments were found proximate to the Agate Basin/Hell Gap point in Unit 51, but given doubts about their association with any recognized cultural feature, these have not been submitted for AMS ${ }^{14} \mathrm{C}$ dating.

In Component $\mathrm{B}$, in addition to the two basally concave lanceolate points, we found one scraper, four bifaces, two biface fragments, one bimarginal flake tool, one unimarginal flake tool, one combination flake tool, and one preform. No charcoal or bone fragments were found that could be used to obtain a radiocarbon date for this component.
The tool assemblage of Component $C$ consisted of the McKean, Hanna and Besant points, the non-diagnostic triangular projectile point and two projectile point tips, a scraper, three gravers or perforators, six bifaces and a hammerstone. Charcoal fragments recovered from the hearth in Unit 52, within Component C, have been submitted for $\mathrm{AMS}{ }^{14} \mathrm{C}$ dating, as well as a large bone fragment found in the upper portion of Unit 53.

\section{Discussion}

While each area was analyzed separately, similar trends were observed in both areas, and material distributions followed similar patterns. A basal component characterized by Agate Basin/Hell Gap projectile points and a reliance on local raw materials was present in both areas. Further, evidence for the diversification of lithic raw material use, with the introduction of more non-local materials in upper higher components, and the intensification of site use over time, occur across both areas.

These patterns have been discernible in spite of highly compressed sediments, and in some cases, a pronounced gradient. It might be expected that slopewash has impacted deposition, particularly in Unit 54, which exhibited a drop of $20 \mathrm{~cm}$ over its $1 \mathrm{~m}$ width. However, the same general trends in lithic raw material distribution were observed in this unit as the rest of Area B. It is nevertheless reasonable to assume that artifacts were subjected to some postdepositional translocation processes (Balek 2002). Bioturbation factors, including tree roots and rodent burrows, were noted throughout both excavation areas, while the deeper component breaks in Unit 52 are possibly attributable to trampling. Despite this, pockets of laterally intact, vertically restricted scatters, as well as spatially restricted features such as the boiling pit in Unit 49 and the hearth in Unit 52, suggest that bioturbation may not have significantly impacted the integrity of the site. Refit analysis may shed further light on this point. At the Bezya site, Le Blanc and Ives (1986) showed that in a forested setting with compressed stratigraphy, refits could be found separated by $40 \mathrm{~cm}$ of vertical deposition. Limited refit analysis with materials from Ahai 
M. Rawluk, A. Reilly, P. Stewart, \& G. YANICKI

Mneh has so far shown that refits can generally be found within the same excavated levels, but not in levels above or below.

We were fortunate to have the earlier Ahai Mneh excavations examined by a specialist in soils at archaeological sites prior to field school activities. Gilliland (pers. comm.) pointed out clear instances in which two to three weak paleosols could be observed in excavation profiles of the original 2008 excavation block and in test pits in low-lying parts of the site. Traces of paleosols were visible in our Area A and B work (Figure 2, marked as IIAhb); these were discontinuous and fragmentary, particularly in Area B. The fact that episodes of deposition and instability separate levels of relative stability (with accompanying pedogenesis) in the soil column at various locations across Ahai Mneh nevertheless lends credence to the discriminations we are making here for artifact depths. While we must always be cautious of factors like bioturbation and trampling, there are indications that the stratigraphy at Ahai Mneh has not been hopelessly compromised. This is likely true of many such sites.

Not all of the empirically segregated components at Ahai Mneh represent distinct cultural occupations, appearing instead to be palimpsests of numerous, temporally unassociated occupancy periods. However, Area B Component A does correlate with a singular diagnostic projectile point style, Agate Basin/Hell Gap, and therefore likely represents a single, albeit ephemeral, occupation. Further, the two fragmentary basally concave lanceolate points found associated with Area B Component B suggest that this, too, may be a distinct occupation. As yet poorly understood, the cultural affiliation and age of this possible second Late Prehistoric component merit further investigation.

The presence of an Agate Basin/Hell Gap component is a significant finding. To date there have been 92 sites in Alberta with identified Agate Basin/Hell Gap components in them (Benders 2010, 19-24). Of these, only five have had projectile points in a known stratigraphic context (Peck 2011, 60-65). The discovery of a stratigraphic component at Ahai Mneh containing Agate Basin/Hell Gap projectile points provides
Identification of a Palaeoindian OCCupation in Compressed Stratigraphy

us with a unique opportunity to learn more about the lithic technology of the Early Prehistoric period. The strong reliance on locally available materials in the basal components of both Areas A and $\mathrm{B}$, together with a tool assemblage consisting primarily of projectile points, scrapers, and edge modified flakes, is consistent with other sites with excavated Agate Basin/Hell Gap components in the province, including the Eclipse site (Fedje 1988; Peck 2011); Minnewanka (Landals 2008); Red Rock Canyon (Reeves 1972); Twin Pines (Ronaghan and Dawe 1998; Peck 2011); and Vermilion Lakes (Fedje 1986).

\section{ConClusion}

The methods used in this study for distinguishing artifacts from different time periods are not only straightforward but cost effective. They require three point provenience measurements, two easily accessible and easy to use software applications (Grapher and Excel), and the motivation to thoroughly analyze the data. While it is true that these techniques are more time consuming than the excavation of sites without piece plotting, the detail of the information retrieved is greatly increased, and the risk of interpretive errors is reduced. Without three point provenience measurements, there is no objective basis to distinguish whether or not artifacts are temporally associated. It is our suggestion that strategic trade-offs be taken into consideration when faced with mitigation of sites that are rich but poorly stratified. We suggest that smaller excavations could be performed with more thorough data collection. This attention to detail will assist in more detailed analysis and understanding of compressed multi-component sites such as Ahai Mneh. Adopting these strategies would not increase the cost of mitigations, but would increase the calibre of the data collected.

\section{ACKNOWLEDGEMENTS}

We would like to express our gratitude to Dr. Jack Ives, instructor of the 2010 IPA Field School at Ahai Mneh, for his guidance, input, and support. The field season was greatly facilitated by the assistance of TransAlta staff, particularly Rod Krause, Janet Janvier and Graeme Fitz. We 
would also like to thank Paul First Nation Chief and Council and community members (especially Violet Poitras, Dennis Paul, and Doris Rain), as well as the rest of the 2010 IPA Field School team: Matthew Belton, Mitchell Hopkins, Vincent Jankunis, Rob Kadis, Sheila Kwasek, Daniel Larson, Melissa Ritz, and Jo-anne Schenk. The assistance of Shirley Harpham, Joanne McKinnon, Erin Plume, and Elizabeth Sawchuk (Department of Anthropology, University of Alberta); Dr. Heinz Pyszczyk, Robin Woywitka, Darryl Bereziuk and Martina Purdon (Archaeological Survey, Historic Resources Management Branch); and Jack Brink and Bob Dawe (Royal Alberta Museum) is gratefully acknowledged. Krista Gilliland, (Department of Biological and Environmental Sciences, University of Stirling) graciously took time out of her busy schedule to assess Ahai Mneh soil profiles for us; we also benefitted from information on Quaternary landforms from Dr. Duane Froese (Department of Earth and Atmospheric Sciences, University of Alberta). Finally, we would like to thank Kristin Soucey (Altamira Consulting) for sharing her insights on working at Ahai Mneh that made our work that much easier.

\section{References Cited}

Andrefsky, William, JR. 1998. Lithics: Macroscopic Approaches to Analysis. Cambridge: Cambridge University Press.

Balek, Cynthia. 2002. "Buried Artifacts in Stable Upland Sites and the Role of Bioturbation: A Review." Geoarchaeology 17 (1): 41-51.

BALL, Bruce F. 2006. "Historical Resources Impact Assessment. TransAlta Highvale Mine Expansion.” ASA Permit 2005-374. Report on file, Archaeological Survey of Alberta, Edmonton.

Benders, Quinn. 2010. "Agate Basin Archaeology in Alberta and Sakatchewan, Canada." MA thesis, University of Alberta.

BINFORD, LEWIS R. 1978. Nunamiut Ethnoarchaeology. New York: Academic Press.

Fedirchuk, Gloria. 1979. "FiPp-33.” Archaeology site inventory form on file, Archaeological Survey of Alberta, Edmonton.

Fedje, Daryl W. 1986. "Banff Archaeology,
1983-1985.” In Eastern Slopes Prehistory: Selected Papers, edited by Brian Ronaghan, pp 25-62. Occasional Paper No. 30. Edmonton: Archaeological Survey of Alberta.

. 1988. "The Norquay and Eclipse Sites: Trans-Canada Highway Twinning Mitigation in Banff National Park." Microfiche Report Series 395. Ottawa: Environment Canada, Parks Service.

Ives, John W. 1985a. The Results of Mitigative Excavations During the Fall of 1979, Strathcona Science Park Archaeological Site (FjPi-29). Manuscript Series Number 3. Edmonton: Archaeological Survey of Alberta.

-. 1985b. A Spatial Analysis of Artifact Distribution on a Boreal Forest Archaeological Site. Manuscript Series Number 5. Edmonton: Archaeological Survey of Alberta.

Landals, Alison J. 2008. "The Lake Minnewanka Site: Patterns in Late Pleistocene Use of the Alberta Rocky Mountains.” PhD diss., University of Calgary.

Le Blanc, Raymond J. 1994. The Crane Site and the Palaeoeskimo Period in the Western Canadian Arctic. Archaeological Survey of Canada Mercury Series Paper 148. Hull: Canadian Museum of Civilization.

Le Blanc, Raymond J., And John W. Ives. 1986. "The Bezya Site: A Wedge-shaped Core Assemblage from Northeastern Alberta." Canadian Journal of Archaeology 10: 59-98.

Peck, Trevor. 2011. Light From Ancient Campfires: Archaeological Evidence for Native Lifeways. Edmonton: AU Press.

Pyszczyk, Heinz. 1981. "Archaeological Investigations at the Strathcona Science Park Site (FjPi-29), Final Report, Permit Number 8074." In Strathcona Site (FjPi-29) Excavations 1978, 1979, and 1980, B. Newton and J. Pollock, J. W. Ives, and H. Pyszczyk. Manuscript Series Nos. 2-4. Edmonton: Archaeological Survey of Alberta.

Reeves, Brian O.K. 1972. The Archaeology of Pass Creek Valley, Waterton Lakes National Park. National Historic Sites Service Manuscript Report No. 61. Ottawa: National and Historic Parks Branch, Department of Indian Affairs and Northern Development. 
M. Rawluk, A. Reilly, P. Stewart, \& G. YANICKI
Identification of a PaLaeoindian Occupation in Compressed Stratigraphy

Ronaghan, Brian, and Robert Dawe. 1998. “An Early Holocene Occupation of James Pass, Alberta." Paper presented at the $31^{\text {st }}$ Annual Canadian Archaeological Association Conference, Victoria.

Soucey, Kristin, Bruce F. Ball, and LoḮc Boscher. 2009. "Historical Resource Impact Mitigation. FiPp-33, FjPp-50,FjPq-36, and FjPq-37. Transalta Generation Partnership. Highvale Mine Pits 3,4, and 5 Expansion," 2 volumes. ASA Permit 2008-320. Report on file, Archaeological Survey of Alberta, Edmonton.

Stevenson, Marc. 1991. "Beyond the Formation of Hearth-Associated Artifact Assemblages." In The Interpretation of Archaeological Spatial Patterning, edited by Ellen M. Kroll and T. Douglas Price. New York: Plenum Press. 